\title{
Experimental investigations and FEM simulations of parameters influencing the Fe-(wt.3\%)Si shearing process
}

\author{
Haykel Marouani $^{1, a}$, Mohamed Rachik ${ }^{2}$ and Eric Hug ${ }^{3}$ \\ 1 Université de Monastir, École Nationale d’Ingénieurs de Monastir, Laboratoire de Génie Mécanique, Avenue Ibn El Jazzar, \\ 5019 Monastir, Tunisie \\ 2 Laboratoire Roberval, UMR CNRS 6253, Université de Technologie de Compiègne, BP 20529, 60205 Compiègne, France \\ 3 Laboratoire de Cristallographie et Sciences des Matériaux, UMR CNRS 6508, Université de Caen, 6 Bd Maréchal Juin, \\ 14050 Caen 4, France
}

Received 2 July 2011, Accepted 3 September 2012

\begin{abstract}
The sheet metal forming by shearing is one of the most used processes in industries. The reliability of the obtained parts depends on geometrical parameters (shape of the tools, punch radius, clearances, velocity...) and materials properties (metal behavior, friction...). In this paper, two experimental parameters are investigated: the punch - die clearance and the punch velocity. A $0.65 \mathrm{~mm}$ thickness sheet of a non-oriented full-process Fe-(wt.3\%)Si is used. The analyses are done through the load-stroke curve and the height repartition of different defects on the part edge. A numerical approach is proposed to simulate the shearing process and to handle the ductile fracture (which is performed using Abaqus/Explicit software). This work is based on a non-iterative explicit algorithm combined with a mesh adaptivity method (Arbitrary Lagrangian Eulerian formulation). The Gurson-Tvergaard-Needleman model is then used to describe the cut edge profile occurring during the process.
\end{abstract}

Key words: Metal shearing / clearance / velocity / numerical simulation / damage

Résumé - Étude expérimentale et numérique du procédé de cisaillage du Fe-3\%Si. Le cisaillage est l'un des procédés les plus utilisés en industrie lors de la mise en forme des métaux en feuilles. La fiabilité des pièces réalisées dépend des paramètres géométriques (forme des outils, rayon de courbure, jeux, vitesse... ) et des propriétés matérielles (comportement, frottement...). Dans cet article, deux paramètres expérimentaux sont examinés : le jeu poinçon-matrice et la vitesse du poinçon. Le matériau utilisé est le Fe$3 \%$ Si présent sous forme de tôle d'épaisseur 0,65 mm. Cette étude est basée sur l'analyse des courbes forcedéplacement du poinçon et sur la hauteur des différents défauts présents sur le bord découpé. Une approche numérique est introduite afin de simuler le procédé de cisaillage et de traiter l'endommagement présent (sous Abaqus/Explicit). Ce travail s'appuie sur un algorithme explicite combiné avec un remaillage adaptatif de type ALE. Le modèle Gurson-Tvergaard-Needleman est alors utilisé pour compléter la description de toutes les phases présente dans ce procédé.

Mots clés : Cisaillage / jeu / vitesse / simulation numérique / endommagement

\section{Introduction}

Blanking, punching, piercing and shearing are the most used processes in sheet metal forming: for the electrical machines industry, for example, most of the required formed parts are cut to length by successive shearing operations. The reliability of the designed machines depends

\footnotetext{
${ }^{a}$ Corresponding author:

Haykel.marouani@enim.rnu.tn
}

on the quality of the sheared parts and on the process parameters: Aggarwall et al. [1] have shown that the sheared parts have to preserve close tolerances concerning volume, weight and geometry. The high quality parts depends on various parameters like geometric configuration (shape of the tools, punch radius), clearance, frictional contact... as demonstrated by Hambli and Guerin [2] and Hernandez et al. [3]. All the involved process parameters have to be understood for every application. However, experimental 


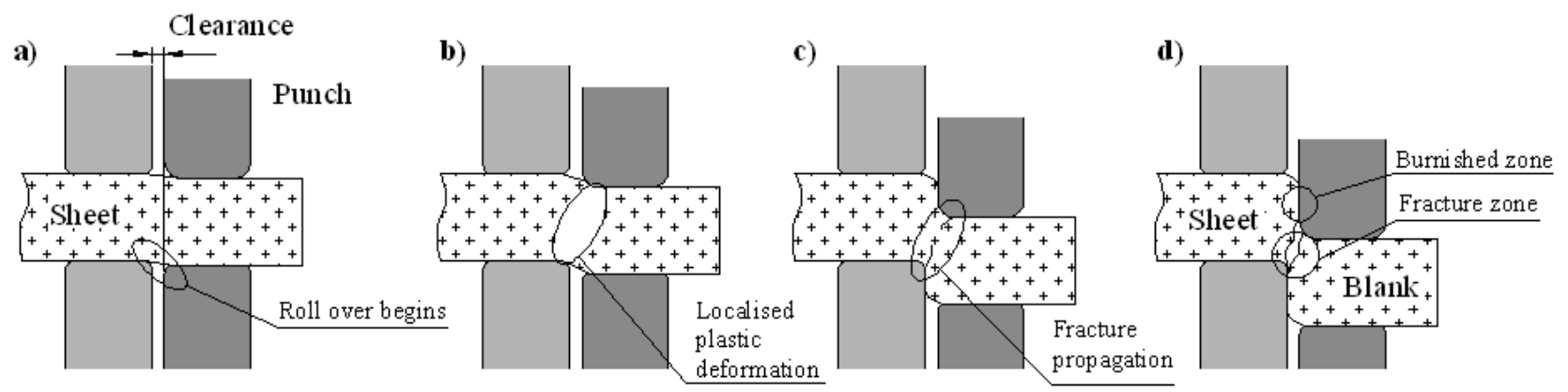

Fig. 1. Phases of shearing process: (a) contact engaging; (b) penetration stage; (c) fracturing stage; (d) full material separation.

and numerical researches on shearing parameters optimization are not as plentiful as for the other processes. Jacobs et al. [4] and Thipprakmas et al. [5] have shown that even if the machine configurations are under control, the influence of the tooling and workpiece related parameters is still complex enough. Moreover, it is time and money consuming to investigate all parameter combinations experimentally. The use of FEM simulations within the manufacturing industry is increasing for optimizing such process as demonstrated by Lemiale et al. [6].

Vaz and Bressan [7] have demonstrated that the shearing process, particularly when shearing rectangular or square sheet, consists of the following classical four phases (Fig. 1). In the first step, the punch pushes down the metal sheet causing the sliding of the sheet over the tools (Fig. 1a). Then the material is deformed elastically and plastically as the punch penetrates further into the sheet: the material is sheared (Fig. 1b). Shearing continues until the remaining cross-section cannot withstand the shearing force and the material fractures any longer (Fig. 1c). The large plastic deformation during this stage causes a burnished zone on the sheared part. At that point, the sheared part is completely separated from the sheet (Fig. 1d).

As with every instrumented process, there is a loadstroke curve correlating to the different phases described above and which is related to the material behaviour [8] (Fig. 2). With the penetration of the punch into the sheet, the load increases continuously and elastically (phase I). The process continues and the yield strength of the material is reached. The material flows along the cutting edges in the direction of the punch penetration and into the gap between the two tools. The material flow causes a strain hardening which results in an increase of the shearing force up to the maximum load. At this time, the cross-section is not reduced and the shearing has not appeared (phase II). Once the pressure at the cutting edges increases sufficiently, the material stops deforming and shearing starts. Due to a decreasing cross section, the cutting force decreases despite the strain hardening of the material (phase III). A fracture starts after the shear strength of the material is exceeded (phase IV). Depending on the process parameters, the incipient cracks will run towards each other separating the sheet and the

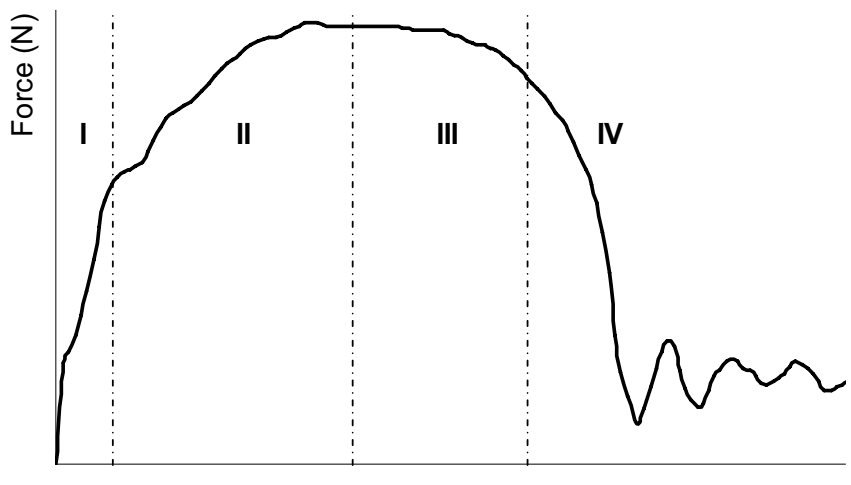

penetration $(\mathrm{mm}) /$ relative penetration $(\%)$

Fig. 2. Typical load-stroke curve.

sheared part. The shearing force decreases rapidly during this phase.

Being based on the initial geometry of the sheet and the process parameters, the flow of material may exhibit different zones and defects (Fig. 3). The part edge typically includes three distinct zones: roll over, burnished zone (also called sheared zone) and fracture zone (including or not burr). The roll over and the burr are results of elastic and plastic deformations at the beginning of the cutting process. An ideal part edge would have almost no roll over, burr or fracture zone and consequently would show almost $100 \%$ shear. However, the formation of the different zones is influenced by a number of parameters such as: material properties and thickness, clearance, tool velocity and part geometry.

Some numerical studies of the forming process have been suggested to assess the influence of the process parameters. The models proposed range from quite simple simulation based on idealized assumptions [9] to some sophisticated approaches that take into account the large strain and the material separation involved in the process. Taupin et al. [10] introduced the use of a ductile fracture criterion to simulate the material separation by deleting the mesh elements. A numerical procedure based on an Arbitrary Lagrangian Eulerian (ALE) formulation combined with re-meshing was proposed [11] and widely applied for further analyses [12]. The ductile fracture is handled with the help of discrete crack propagation. 


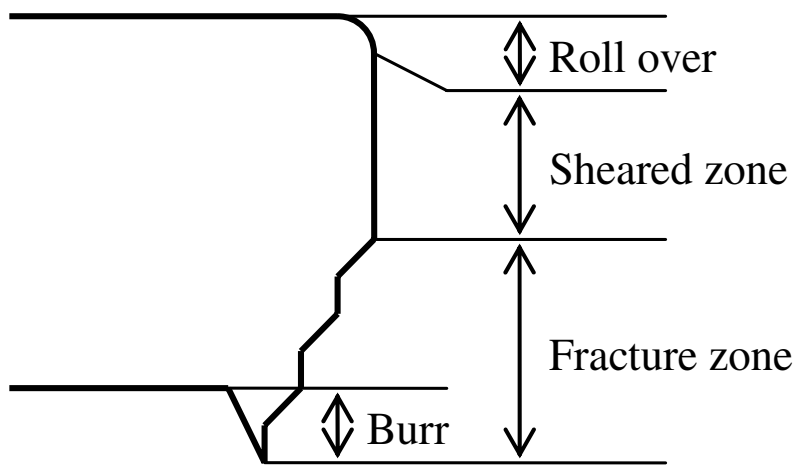

Fig. 3. Cut edge profile on the sheared surface.

Table 1. Nominal composition of used material.

\begin{tabular}{cccc}
\hline $\mathrm{Fe}(\%)$ & $\mathrm{Si}(\%)$ & $\mathrm{Mn}(\%)$ & $\mathrm{C}(\%)$ \\
\hline 96.5 & 2.4 & 1 & 0.1 \\
\hline
\end{tabular}

Recently, the coupled damage model has used to predict the shape of the cut edge of the blanked parts $[13,14]$. The previously cited works were not exhaustive since several researches are carried out in this field contributing to a best understanding of the shearing process.

The present work discusses some experimental parameters impact on the quality of the sheared parts: the clearance between the punch and the die and the shearing velocity. The experimental observations are made through two ways: the load-stroke curve analysis and the part edge observation. Numerical simulations of all experimental used configurations are performed using ABAQUS software. A particular attention is paid to the sheet metal constitutive model and the treatment of large distortion of the mesh elements that occurs during the calculation and leads to strain localization, element degradation and important errors. In order to validate this work, the numerical results obtained are compared to the measurements.

\section{Sheet metal shearing experimental aspects}

The used material and experimental set-up are presented in this section and followed by the principal results. Then, we discuss the clearance and velocity impact on the maximum shearing force and on the cut edge profile.

\subsection{Material characterization}

The material investigated in the framework of this study is a $0.65 \mathrm{~mm}$ thick (by $23 \mathrm{~mm}$ in width) sheet of a non-oriented fully process Fe-(3wt.\%)Si steel designed by "Sollac M800-65A". It is widely used in magnetomechanical engineering. The composition is presented on Table 1.

The tensile properties of the material are shown in Table 2. The work hardening characteristic, i.e. the stressstrain relation of the material was approximated by the Ludwik law $\sigma=K \cdot \varepsilon^{n}$.
Table 2. Mechanical properties of material.

\begin{tabular}{lc}
\hline Young's modulus (GPa) & 195 \\
Poisson's ratio & 0.29 \\
Yield strength $(\mathrm{MPa})$ & 310 \\
Ultimate tensile strength $(\mathrm{MPa})$ & 433 \\
Strength coefficient $K(\mathrm{MPa})$ & 750 \\
Work hardening exponent $n$ & 0.245 \\
Density $\left(\mathrm{kg} \cdot \mathrm{m}^{-3}\right)$ & 7800 \\
\hline
\end{tabular}

Table 3. Shearing tests.

\begin{tabular}{|c|c|c|c|c|c|c|c|}
\hline & & \multicolumn{6}{|c|}{ Clearances (\%) } \\
\hline & & 3.1 & 7.7 & 10.8 & 15.4 & 18.5 & 23.1 \\
\hline Velocity & 58 & $\bullet$ & $\bullet$ & $\bullet$ & $\bullet$ & $\bullet$ & $\bullet$ \\
\hline$\left(\mathrm{mm} \cdot \mathrm{s}^{-1}\right)$ & 154 & $\bullet$ & $\bullet$ & $\bullet$ & $\bullet$ & $\bullet$ & $\bullet$ \\
\hline
\end{tabular}

\subsection{Experimental set-up}

Various shearing tests were carried out using a mechanical press (200t, 80 RPM). A specific tool was realized for this study and adapted with the press characteristics. The tools were equipped with a piezoelectric sensor and a signal acquisition and processing system to measure the cutting force during the shearing process. The punch used was open and straight (Fig. 4). The shearing configuration does not incorporate a sheared part support or a sheet holder. The punch corner radius is equal to $0.02 \mathrm{~mm}$.

The shearing experiments were carried out under various conditions. For the clearance effect study, the punch - die distances are adjusted to obtain the six appropriated clearances ranging from 3.1 to $23.1 \%$ (the clearance is expressed as a percentage of the sheet thickness). For every clearance, two punch velocities were applied (58 and $154 \mathrm{~mm} . \mathrm{s}^{-1}$ ) as shown in Table 3.

\subsection{Results and discussion}

In this section, the effects of the clearance and velocity on the shearing process are evaluated through the loadstroke curve and the cut edge profile.

\subsubsection{Clearance impact}

The influence of some clearances on the force versus penetration curve is illustrated in Figure 5. It clearly shows that, as expected [15], the maximum punch force increases when the clearance decreases (Fig. 6). In addition, the clearance is shown to affect the punch penetration at fracture, and consequently, the shape of the part edge.

To investigate the influence of clearance on the shape of the part edge, the sheared parts with different test configurations are analyzed using SEM analysis (Fig. 7). The height repartitions of roll over, burnished zone and fracture zone are illustrated in Figure 8. Even if the measurement of the part edge zones is not an easy task, the 


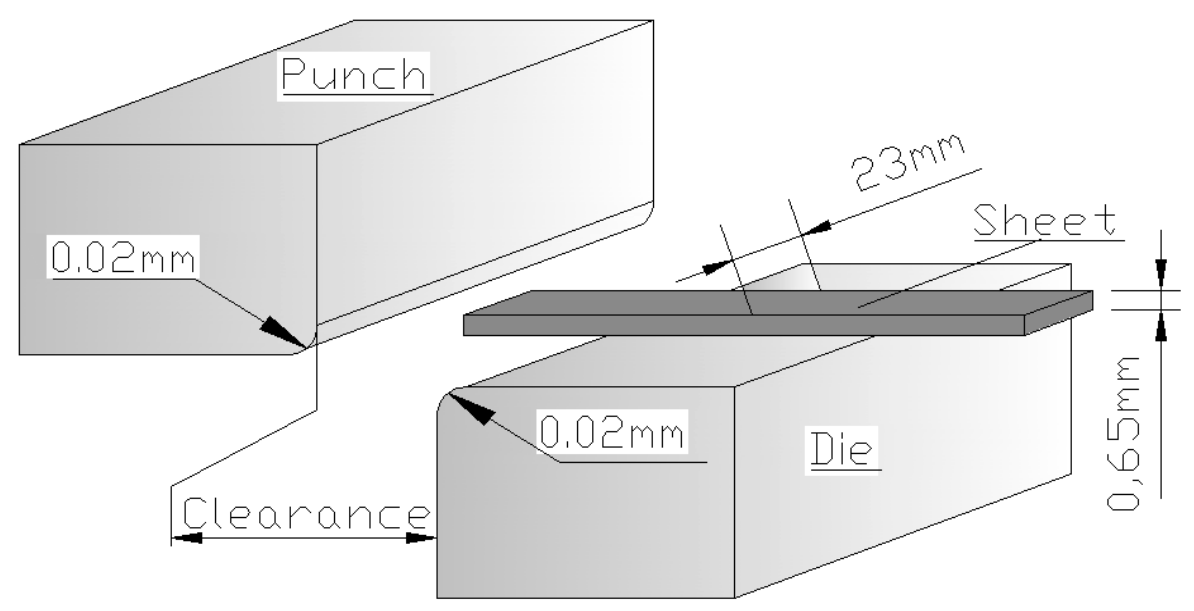

Fig. 4. Schematic description of the shearing test.
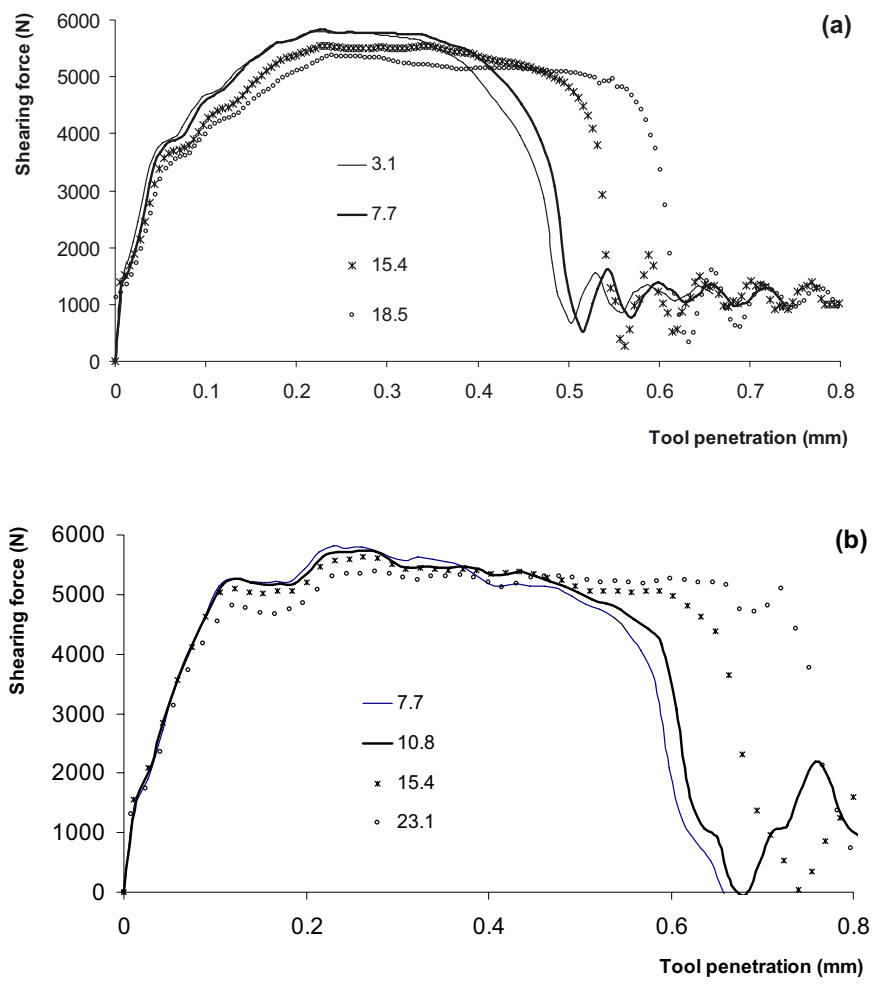

Fig. 5. Shearing force-penetration curve for various values of the clearance: (a) punch velocity: $58 \mathrm{~mm} . \mathrm{s}^{-1}$; (b) punch velocity: $154 \mathrm{~mm} \cdot \mathrm{s}^{-1}$

micrograph analysis shows that the roll over is quite constant. It represents $9-14 \%$ of the thickness. Unlike the fracture zone, the sheared zone increases with the clearances for the two punch velocities.

\subsubsection{Velocity impact}

Concerning the punch velocity effect, Figure 9 shows that the tool penetration at fracture is quite sensitive

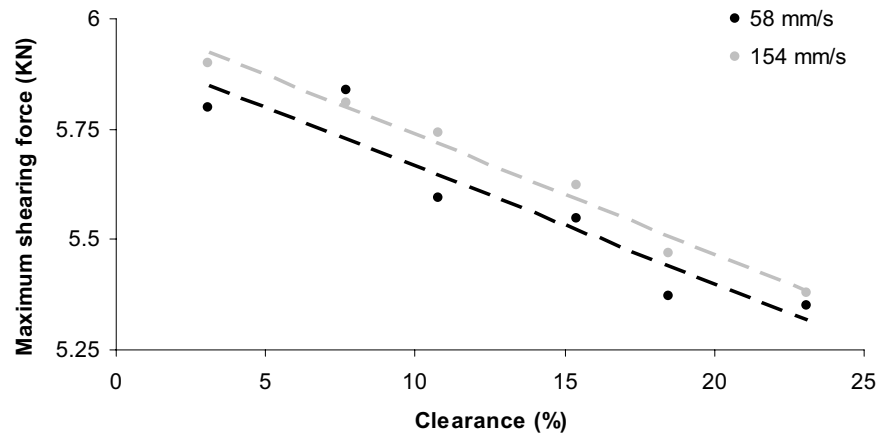

Fig. 6. Maximum shearing force evolution with clearance.

to velocity for all the clearances used. Indeed, the maximum shearing force is not affected by the punch velocity: a negligible difference exists between speeds of 58 and 154 mm.s ${ }^{-1}$.

\section{Numerical aspects}

Numerical simulation of sheet metal forming process is the object of several studies. Different approaches are proposed to simulate the shearing process and to handle ductile fracture. For this purpose, uncoupled and coupled damage models are combined with mesh adaptivity and other constituents of the finite-element method. In the following section, we briefly describe the used finite-element model which was also previously validated for numerical investigation on the blanking process [16].

\subsection{Finite-element model}

As the shearing process leads to the material separation, a particular attention must be paid to the finiteelement model, particularly, the load stepping algorithm and the mesh adaptivity that ensure the solution reliability for high strain level. Because of the high non-linearities 

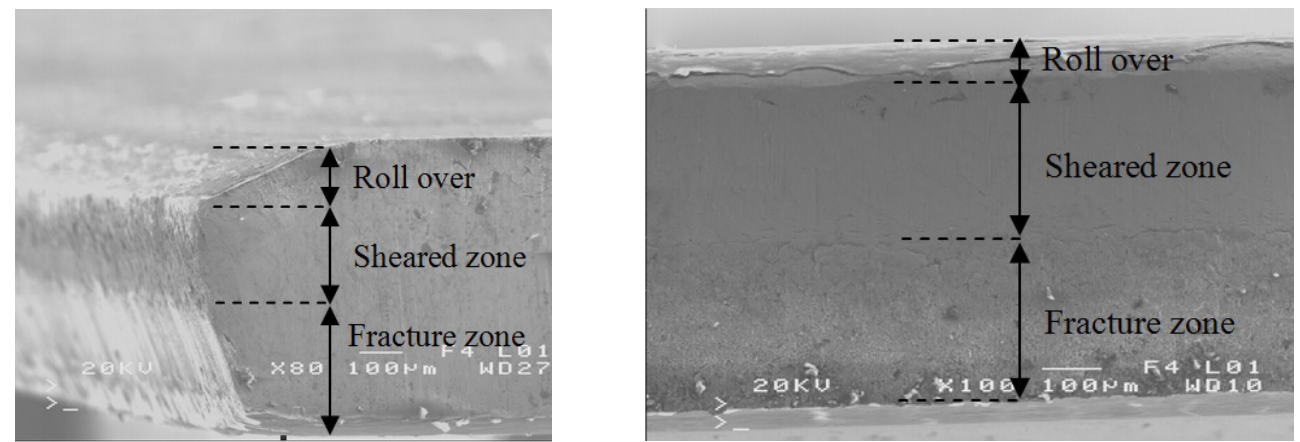

Fig. 7. SEM micrograph analysis of the shape of the part edge with the shearing configurations (clearance: 10.8\%; velocity: $\left.58 \mathrm{~mm} \cdot \mathrm{s}^{-1}\right)$.
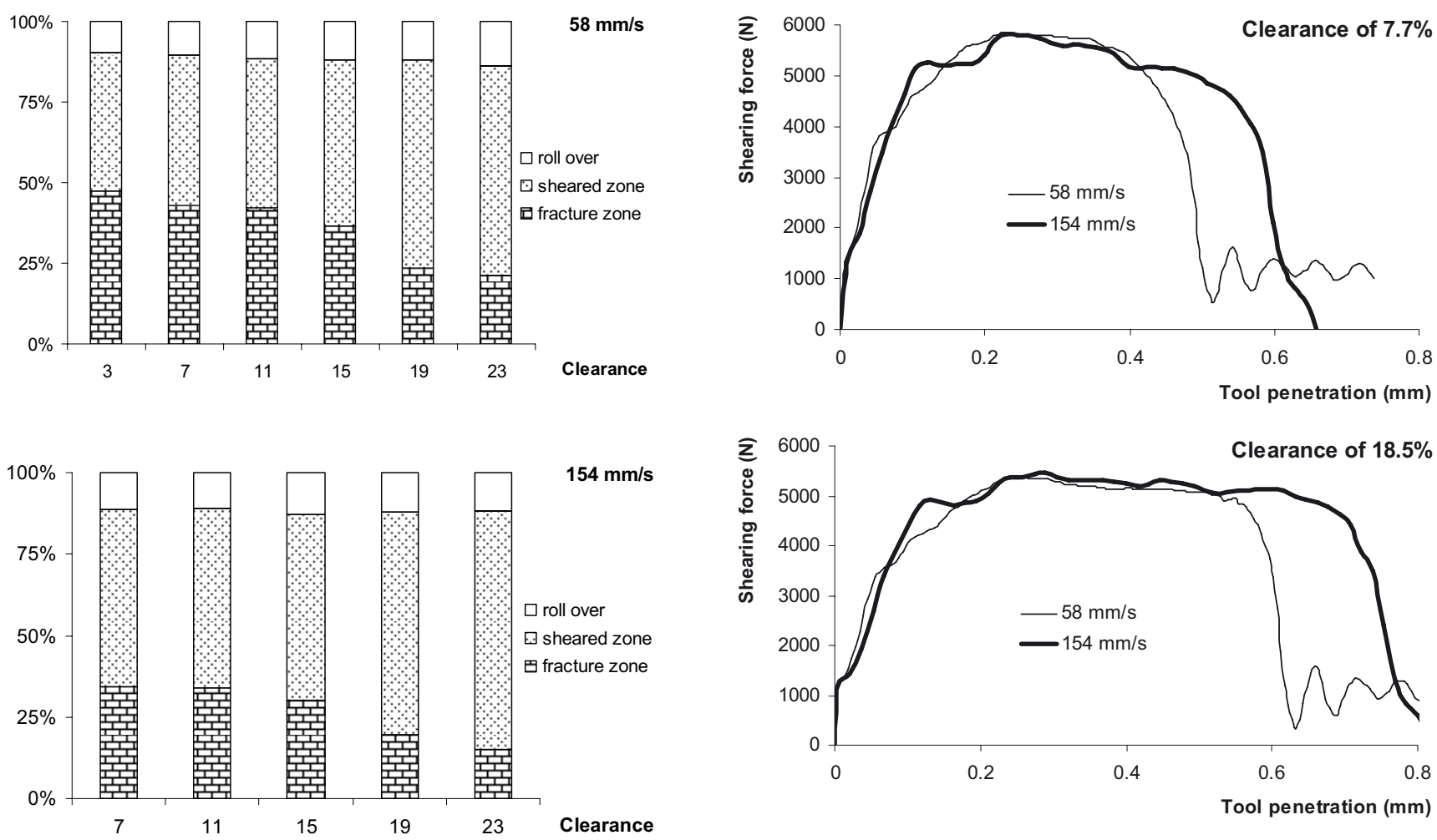

Fig. 8. Comparison of height ratio of defects zones for different punch velocities.

associated with shearing process, the classical iterative Newton-Raphson method can involve convergence problems. Therefore, it is not adapted to this research. In this work, we focus on the non-iterative explicit approach. The displacement solution is advanced with the help of the central finite difference integration scheme.

Another aspect of the finite-element simulation of the shearing process is the large distortion of the elements that occurs during the calculation and leads to strain localization, element degradation and important errors that make the solution unreliable. Among the several mesh adaptivity methods, the ALE (Arbitrary Lagrangian Eulerian) formulation seems to be the most convenient one for blanking simulation since this process involves large

Fig. 9. Shearing force-penetration curve for the used velocities.

inelastic deformations. The ALE method consists of two fundamental stages: creating new mesh (mesh smoothing) and remapping the solution variables from the old mesh to the new one (advection). In this work, the adaptive meshing procedure of ABAQUS Explicit Software is used.

The mesh smoothing is performed by means of a simple volume smoothing method that relocates a node by computing a volume weighed average of the element centres in the elements surrounding the node. As the finite difference explicit scheme is conditionally stable, and as the stability requirement limits the amount of motion within a time increment, an operator split is used to decouple the Lagrangian motion from the mesh motion. The advection is performed by means of a second order 
method that is described in ABAQUS Explicit user's manual.

For this work, the adaptive mesh domain is all the solution elements in the smoothed mesh zone (Fig. 10). The adaptive meshing is performed each increment. To improve the mesh quality, the number f mesh sweep to be performed in each adaptive mesh increment is 20 .

\subsection{Sheet metal constitutive model}

Among several existing sheet metal forming processes, the shearing process stands apart since plastic straining is followed by ductile fracture and material separation. This involves some additional difficulties, particularly when dealing with the numerical simulation of this process. Consequently, a particular attention must be paid to the sheet constitutive model. In previous works [16], we successfully used the Gurson-Tvergaard-Needleman model to handle ductile fracture. The yielding function is extended to porous metal plasticity as demonstrated by Gurson [17] and Tvergaard [18]:

$$
\Phi=\frac{\sigma_{\mathrm{eq}}}{\bar{\sigma}}+2 q_{1} f^{*} \cosh \left(-q_{2} \frac{3 \sigma_{h}}{2 \bar{\sigma}}\right)-\left(1+q_{3} f^{* 2}\right)=0
$$

with $\sigma_{\text {eq }}=\sqrt{\frac{3}{2} \sigma_{i j}{ }^{\prime} \cdot \sigma_{i j}{ }^{\prime}}$ the von Mises equivalent stress, $\sigma^{\prime}$ the Cauchy stress deviator, $\bar{\sigma}$ the yield stress, $\sigma_{h}$ the hydrostatic stress $\left(\sigma_{h}=-\frac{1}{3} \sigma_{i i}\right)$ and $q_{1}, q_{2}$ and $q_{3}$ are adjustable material parameters.

The three stages of ductile fracture (void initiation, void growth and void coalescence) and the rapid loss of the load carrying capacity of the material are modeled using the variable $f *$ that is related to the damage variable $f$ (void volume fraction) as follows:

$$
f^{*}=\left\{\begin{array}{l}
f \quad \text { if } \quad f \leq f_{\mathrm{c}} \\
f_{\mathrm{c}}+\frac{\bar{f}_{\mathrm{F}}-f_{\mathrm{c}}}{f_{\mathrm{F}}-f_{\mathrm{c}}}\left(f-f_{\mathrm{c}}\right) \quad \text { if } \quad f_{\mathrm{c}} \leq f \leq f_{\mathrm{F}} \\
\bar{f}_{\mathrm{F}} \quad \text { if } \quad f \geq f_{\mathrm{F}}
\end{array}\right.
$$

where $f_{\mathrm{c}}$ is the critical void volume fraction and $f_{\mathrm{F}}$ is the void volume fraction at failure:

$$
\bar{f}_{\mathrm{F}}=1 / q_{1} \text { when } q_{3}=q_{1}^{2}
$$

The evolution of void volume fraction comes from the growth of the existing void and the nucleation of new void:

$$
\dot{f}=\dot{f}_{\text {gr }}+\dot{f}_{\text {nucl }}
$$

The void growth $\dot{f}_{\text {gr }}$ is related to the compressibility of the surrounding material. It depends on the volumetric part of plastic strain rate $\dot{\varepsilon}_{k k}^{p}$ :

$$
\dot{f}_{\mathrm{gr}}=(1-f) \dot{\varepsilon}_{k k}^{p}
$$

The void nucleation $\dot{f}_{\text {nucl }}$ is described by a normal distribution around a mean value [19]:

$$
\dot{f}_{\text {nucl }}=\frac{f_{N}}{S \sqrt{2 \pi}} \exp \left[-\frac{1}{2}\left(\frac{\bar{\varepsilon}^{p}-\varepsilon_{N}}{S}\right)\right] \cdot \dot{\bar{\varepsilon}}^{p}
$$

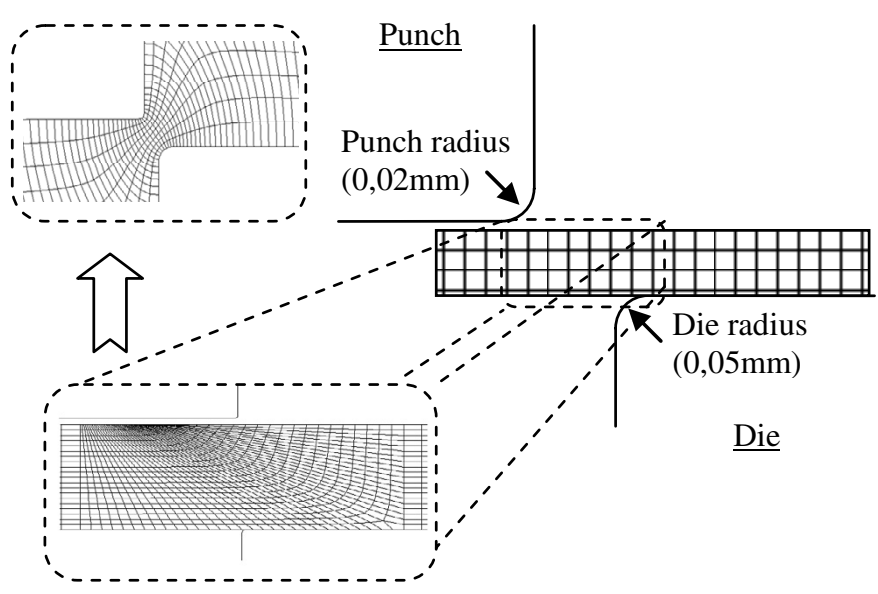

Fig. 10. Finite-element model for the shearing test simulation.

Table 4. Material input data for Fe-(wt.3\%)Si steel.

\begin{tabular}{cc}
\hline Plasticity & \\
\hline$K(\mathrm{MPa})$ & 750 \\
$n$ & 0.245 \\
Damage & \\
Yielding & \\
$q_{1}$ & 1.5 \\
$q_{2}$ & 1 \\
$q_{3}$ & 2.25 \\
Nucleation & \\
$S$ & 0.1 \\
$\varepsilon_{N}$ & 0.5 \\
$f_{N}$ & 0.04 \\
Failure & \\
$f_{c}$ & 0.11 \\
$f_{F}$ & 0.12 \\
\hline
\end{tabular}

where $\bar{\varepsilon}^{p}$ is the equivalent plastic strain, $\dot{\bar{\varepsilon}}^{p}$ is the equivalent plastic strain rate, $f_{N}$ is the volume fraction of nucleating void, $\varepsilon_{N}$ is the mean strain for void nucleation and $S$ is the standard deviation.

\subsection{Validation on shearing tests}

The shearing tests described previously are simulated using a 2D solid finite element model. This finite element model is described in Figure 10. The tools (punch and die) are modeled using rigid bodies. Along the specimen left boundary the motion is completely free. Along the right boundary, the movement is fully constrained. The other boundaries are in interaction with the contacting bodies. The contact is described with a Coulomb friction model with a coefficient of friction $\mu$ equal to 0.15 . Quadrangular plane strain elements (CAX4R: a four node bilinear axisymetric quadrilateral element with reduced integration) were used with fine mesh in the area subjected to high strain (1024 elements were used, among them 960 for the highly sheared area, close to the edge of punchs).

The material input data for the investigated Fe(wt.3\%)Si steel are summarized in Table 4. The Ludwik law parameters $K$ and $n$ identified from tensile tests are 

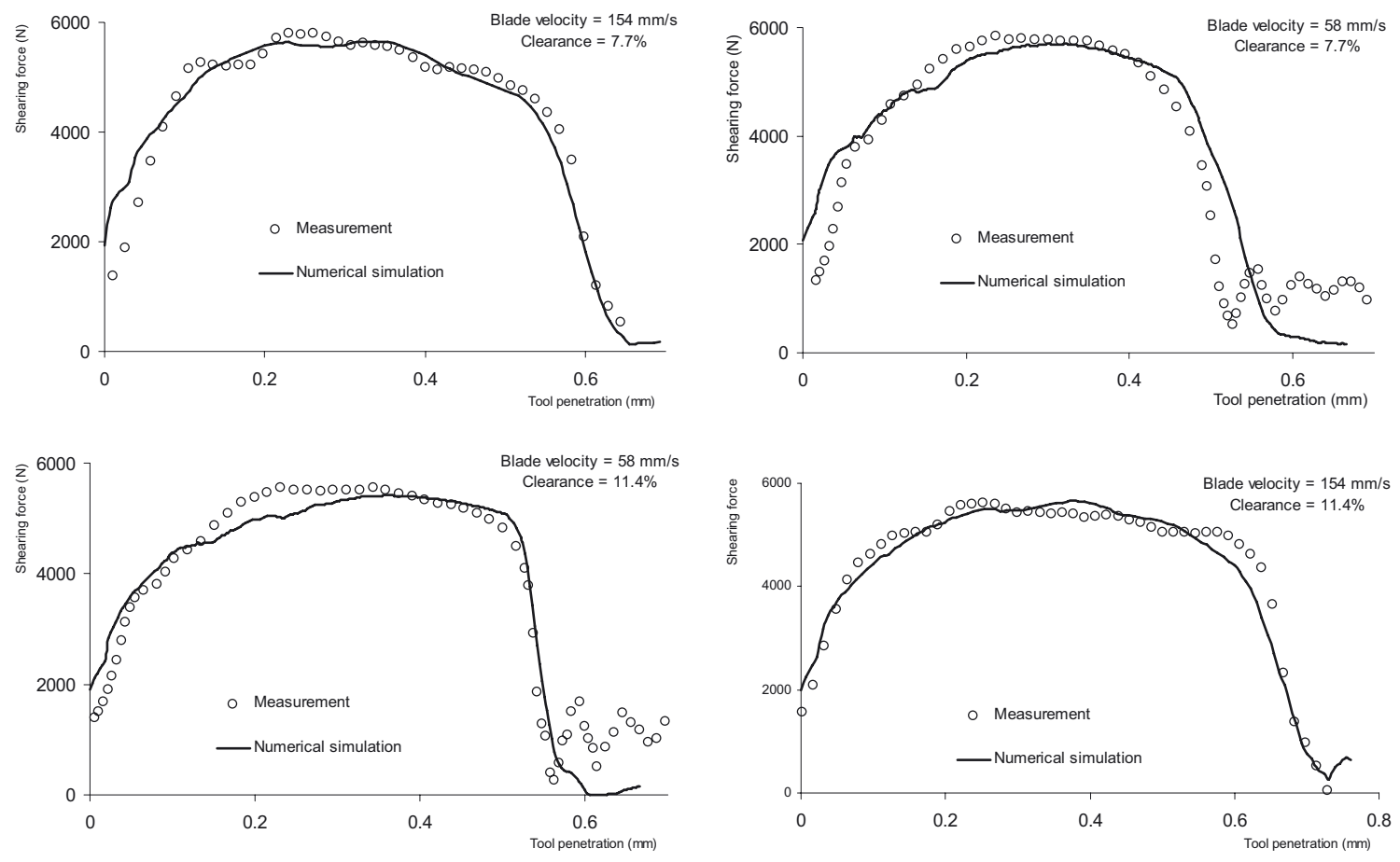

Fig. 11. Comparison between measurement and F.E. prediction.

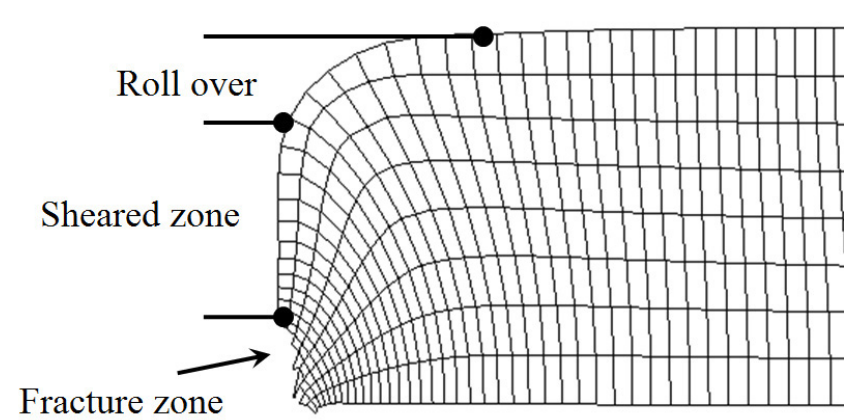

Fig. 12. Numerical cut edge profile on the sheared surface.

used to describe the plastic flow. The various damage parameters are chosen according to literature [20].

To show the numerical model ability to assess the influence of clearance and punch velocity, Figure 11 gives a comparison between the measurements and the numerical results. For example, the results are compared to both punch velocity and two clearance values $(7.7 \%$ and $11.4 \%)$. The numerical results are in good agreements with the measurements. The FEM package used predicts correctly the maximum shearing force and the tool penetration at fracture.

To complete this validation, a comparison between experimental and numerical height of the defects zone is made. Figure 12 shows the numerical shape of the part that is cut. The roll over and the sheared zone are easily identified. The fracture zone is assumed the set of elements that have a void volume fraction higher than $11 \%$. Figure 13 shows that the numerical results for roll over

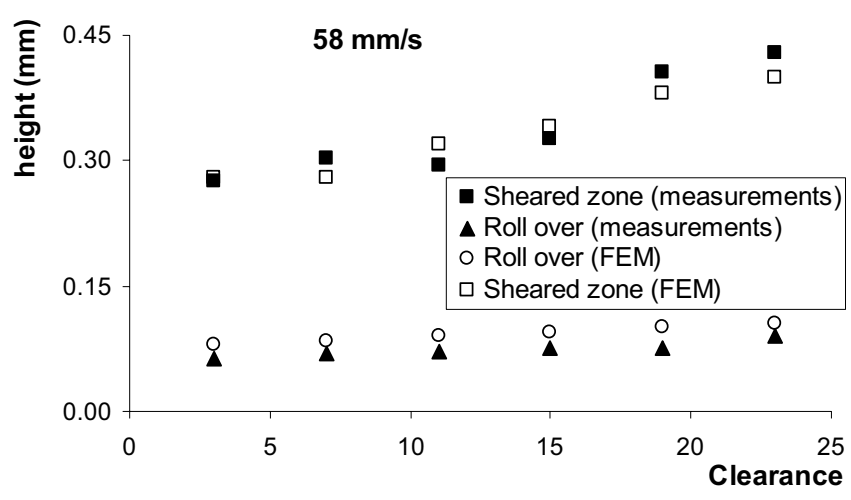

Fig. 13. Numerical and experimental comparison between shared zone and roll over height for different clearances (velocity of $58 \mathrm{~mm} . \mathrm{s}^{-1}$ ).

and sheared heights are in good agreement with the measurements.

\section{Conclusion}

Shearing is one of the main sheet metal forming processes, so attention must be focused on its experimental investigation and numerical simulation. In this work, the experimental researches were devoted to the influence of clearance and punch velocity. It can be concluded that the clearance between punch and stationary one and the velocity of the cutting tool will affect the precision of the shape and the dimension dramatically. The maximum shearing force increases when the clearance decreases. It has been shown that FEM simulation of the process used 
in this work is in accord with all experimental results. The sheet metal constitutive model combined with mesh adaptivity and other components of the finite-element model are able to predict the different metal behaviour during the process. The Gurson-Tvergaard-Needleman model is a sufficient damage law used to simulate the metal shearing.

\section{References}

[1] S. Aggarwal, B. Bhushan, N. Katsube, Three-dimensional finite element analysis of the magnetic tape slitting process, J. Mater. Process. Technol. 170 (2005) 71-88

[2] R. Hambli, F. Guerin, Application of a neural network for optimum clearance prediction in sheet metal blanking processes, Finite Elem. Anal Des. 39 (2003) 1039-1052

[3] J.J. Hernández, P. Franco, M. Estrems, F. Faura, Modelling and experimental analysis of the effects of tool wear on form errors in stainless steel blanking, J. Mater. Process. Technol. 180 (2006) 143-150

[4] O. Jacobs, W. Dalock, H. Demenus, Shear cutting of thermoplastic foils, Polym. Tes. 22 (2003) 579-587

[5] S. Thipprakmas, S. Rojananan, P. Paramaputi, An investigation of step taper-shaped punch in piercing process using finite element method, J. Mater. Process. Technol. 197 (2008) 132-139

[6] V. Lemiale, J. Chambert, P. Picart, Description of numerical techniques with the aim of predicting the sheet metal blanking process by FEM simulation, J. Mater. Process. Technol. 209 (2009) 2723-2734

[7] J.M. Vaz, J.D. Bressan, A computational approach to blanking processes, J. Mater. Process. Technol. 125-126 (2002) 206-212

[8] W. Klingenberg, U.P. Singh, Comparison of two analytical models of blanking and proposal of a new model, Int. J. Mach. Tools Manuf. 45 (2005) 519-527

[9] S.K. Maiti, A.A. Ambekar, U.P. Singh, P.P. Date, K. Narasimhan, Assessment of influence of some process parameters on sheet metal blanking, J. Mater. Process. Technol. 102 (2000) 249-256

[10] E. Taupin, J. Breitling, W.T. Wu, T. Atlan, Material fracture and burr formation in blanking results of FEM simulations and comparison with experiments, J. Mater. Process. Technol. 59 (1996) 68-78
[11] D. Brokken, W.A.M. Brekelmans, F.T.P. Baaijens, Predicting the shape of blanked products: a finite element approach, J. Mater. Process. Technol. 103 (2000) $51-6$

[12] A.M. Goijaerts, L.E. Govaert, F.T.P. Baaijens, Evaluation of ductile fracture models for different metals in blanking, J. Mater. Process. Technol. 110 (2001) 312-323

[13] M. Rachik, J.M. Roelandt, A. Maillard, Some phenomenological and computational aspects of sheet metal blanking simulation, J. Mater. Process. Technol. 128 (2002) 256-265

[14] J. Mediavilla, R.H.J. Peerlings, M.G.D. Geers, An integrated continuous-discontinuous approach towards damage engineering in sheet metal forming processes, Eng. Fract. Mech. 73 (2006) 895-916

[15] Z. Tekiner, M. Nalbant, H. Gürün, An experimental study for the effect of different clearances on burr, smooth-sheared and blanking force on aluminium sheet metal, Mater. Des. 27 (2006) 1134-1138

[16] H. Marouani, A. Ben Ismail, E. Hug, M. Rachik, Ratedependent constitutive model for sheet metal blanking investigation, Mater. Sci. Eng. A. 487 (2008) 162-170

[17] A.L. Gurson, Continuum theory of ductile rupture by void nucleation and growth: Part I - Yield criteria and flow rules for porous ductile media, J. Eng. Mater. Technol. 99 (1977) 1-15

[18] V. Tvergaard, Influence of voids on shear band instabilities under plane strain conditions, Int. J. Fract. Mech. 17 (1981) 389-407

[19] C.C. Chu, A. Needleman, Void Nucleation Effects in Biaxially Stretched Sheets, J. Eng. Mater. Technol. 102 (1980) 249-256

[20] M. Springmann, M. Kuna, Identification of material parameters of the Gurson-Tvergaard-Needleman model by combined experimental and numerical techniques, Comp. Mater. Sci. 33 (2005) 501-509

[21] J.M. Vaz, J.D. Bressan, A computational approach to blanking processes. J. Mater. Process. Technol. 125-126 (2002) 206-212 